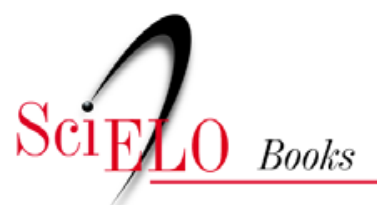

\title{
Capítulo 6 - O uso da autoscopia como aliada na formação continuada de professores de Sala de Recursos Multifuncionais
}

\author{
Thatyana Machado Silva \\ Leila Regina d’Oliveira de Paula Nunes
}

\section{SciELO Books / SciELO Livros / SciELO Libros}

SILVA, T. M. and NUNES, L. R. O. P. O uso da autoscopia como aliada na formação continuada de professores de Sala de Recursos Multifuncionais. In: NUNES, L. R. O. P., and SCHIRMER, C. R., orgs. Salas abertas: formação de professores e práticas pedagógicas em comunicação alternativa e ampliada nas salas de recurso multifuncionais [online]. Rio de Janeiro: EDUERJ, 2017, pp. 137-168. ISBN: 978-85-7511-452-0. Available from: doi: 10.7476/9788575114520.008. Also available in ePUB from: http://books.scielo.org/id/xns62/epub/nunes-9788575114520.epub.

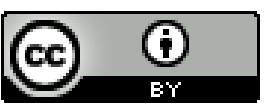

All the contents of this work, except where otherwise noted, is licensed under a Creative Commons Attribution 4.0 International license.

Todo o conteúdo deste trabalho, exceto quando houver ressalva, é publicado sob a licença Creative Commons Atribição 4.0.

Todo el contenido de esta obra, excepto donde se indique lo contrario, está bajo licencia de la licencia $\underline{\text { Creative Commons }}$ Reconocimento 4.0. 


\title{
Capítulo 6-O uso da autoscopia como aliada na formação continuada de professores de Sala de Recursos Multifuncionais
}

\author{
Thatyana Machado Silva ${ }^{1}$ \\ Leila Regina d'Oliveira de Paula Nunes ${ }^{2}$
}

$\mathrm{Na}$ última década, o governo federal buscou propagar os referenciais da educação inclusiva em todo o país, a fim de estabelecer um novo marco organizacional na educação brasileira (MEC/SEESP, 2008, p. 15). Diante de tantas mudanças, é essencial que haja uma reestruturação na postura dos professores, que não podem mais olhar a escola de maneira homogênea, mas precisam dar início a um processo crítico-reflexivo de modo a fazer valer o direito de educação para todos.

Ao pensar na Política Nacional de Educação Especial na Perspectiva da Educação Inclusiva (MEC/SEESP, 2008), pesquisas do Observatório Nacional de Educação Especial (Oneesp) ${ }^{3}$ apontam que há uma grande escassez

1 Mestre em Educação pelo Programa de Pós-Graduação em Educação da UERJ. Secretaria Municipal de Educação de Rio das Ostras. E-mail: thatyana.ms@gmail.com.

2 Professora titular da Faculdade de Educação e do Programa de Pós-Graduação em Educação da UERJ. E-mail: leilareginanunes@terra.com.br.

3 O Oneesp é um grupo de pesquisa em nível nacional, iniciado em 2011, cujos primeiros estudos foram realizados em 56 municípios provenientes de 17 estados brasileiros, 
de professores habilitados a trabalhar nas Salas de Recursos Multifuncionais (SRMs) e a exercer o Atendimento Educacional Especializado (AEE). As pesquisas do Oneesp (2014) confirmam, ainda, que os professores de SRM não se sentem aptos para oferecer o AEE a toda demanda que foi estabelecida como público-alvo da educação especial - o que inclui o trabalho não só com os diferentes tipos de deficiência, mas também com pessoas de diferentes faixas etárias, visto que a educação inclusiva perpassa da educação infantil até o ensino superior. Isso faz com que os professores assumam um problema de cunho político-administrativo como se fosse uma falha pessoal por ter uma formação precária.

Mendes, Vilaronga e Zerbato (2014) tecem uma enorme crítica ao modelo de Sala de Recursos vigente, referindo-se a ele como sendo um modelo econômico para o governo, pois centraliza diversos materiais, equipamentos e outros apoios em um mesmo local. Segundo as autoras, "esse modelo coloca obstáculos instransponíveis à formação dos professores, pois esses são obrigados a dominar conhecimentos e habilidades de ensino de diferentes populaçōes da Educação Especial" (Mendes et al., 2014, p. 25).

A angústia causada nos professores de Sala de Recursos, ao perceberem a enorme lista de suas atribuiçóes, faz com que, muitas vezes, eles assumam para si aquilo que é papel do governo como um todo. Mendes et al. (2015, p. 30) afirmam que "predomina no discurso político a responsabilidade deste profissional em adquirir múltiplas competências”, como se o professor fosse

a saber: Alagoas, Amapá, Bahia, Espírito Santo, Goiás, Maranhão, Mato Grosso do Sul, Minas Gerais, Rio de Janeiro, Rio Grande do Norte, Rondônia, São Paulo, Santa Catarina, Sergipe, Paraíba e Paraná. A princípio, o projeto foi composto por 25 pesquisadores que faziam parte de 22 universidades e de 18 programas de pós-graduação. Com o passar do tempo, esse número alastrou-se de modo que, em 2014, haviam participado do projeto 808 pessoas, sendo 203 pesquisadores (49 da rede nacional, 72 das redes estaduais de pesquisa, 77 pesquisadores colaboradores e 5 em estágios de pós-doutorado); 217 estudantes (115 alunos de 22 cursos de graduação, 55 de 14 diferentes programas de pós-graduação, 10 de cursos de especialização e 37 de graduação envolvidos em dois Programas de Incentivo à Docência - PIBID - de suas universidades); 446 professores especializados de SRM dos vários estados; e 36 gestores municipais da educação especial (Mendes e CIA, 2014, p. 20). 
o responsável por buscar sua própria formação a fim de cumprir com todas as especificidades exigidas pelo MEC. Em outas palavras, pode-se dizer que há sobre o professor do AEE a expectativa de que ele seja multifuncional em suas atribuições e açôes pedagógicas; sendo essa uma exigência que deveria pertencer ao espaço físico da Sala de Recursos, e não ao profissional que nela atua.

Ao observar tais questôes e considerar a urgência em discutir assuntos relacionados à educação inclusiva e à formação exigida dos professores para trabalhar nessa área específica, um grupo de pesquisadores ligados ao grupo de pesquisa do Laboratório de Tecnologia Assistiva da Universidade do Estado do Rio de Janeiro (LATECA) desenvolveu, junto à Oficina Vivencial de Ajudas Técnicas (um dos serviços oferecidos pelo Instituto Helena Antipoff), um processo de formação continuada para professores que trabalham nas Salas de Recursos Multifuncionais do Rio de Janeiro.

Foi assim que, em 2013, Schirmer e Nunes iniciaram uma pesquisa intitulada "A Formação Continuada de Professores das Salas de Recursos Multifuncionais do Rio de Janeiro em Tecnologia Assistiva”, financiada pela FAPERJ e pelo CNPq. A pesquisa teve como objetivo principal formar professores de SRM em Tecnologia Assistiva (TA) para que, ao estarem devidamente preparados, tivessem condiçóes de atender a seus alunos e dar o suporte necessário para o corpo docente da escola, bem como para os professores de SRM que fazem parte de suas Coordenadorias Regionais de Educação (CRE).

A pesquisa teve início com um curso de capacitação em TA e CAA para os professores participantes. Logo após a oferta do curso, Schirmer levou para o grupo de pesquisa um vídeo que mostra a conversa com um de seus pacientes durante o atendimento em seu consultório de fonoaudiologia e solicitou aos professores que analisassem o modo como ela interagiu com seu paciente, bem como os recursos que ela usou para conduzir a conversa e possibilitar uma comunicação autônoma daquele sujeito. Após isso, foi proposto que os professores filmassem o atendimento que realizavam na Sala de Recursos com os alunos que não apresentavam linguagem oral e levassem o vídeo para a próxima reunião de pesquisa, com a finalidade de exibir e avaliar como estavam suas práticas pedagógicas em relação aos conteúdos que foram experimentados no curso frequentado.

Essa proposta foi lançada de modo que os professores tivessem a liberdade de escolher participar ou não desse momento da pesquisa, não sendo 
eles obrigados a filmar suas aulas. Inicialmente, três professoras aceitaram participar dessa etapa e levaram suas experiências registradas em gravações de vídeo. Esse momento da pesquisa foi considerado como "Análise de Desempenho" e era realizado de maneira que todos assistissem juntos ao vídeo e analisassem a atuação da professora com o aluno que apresentasse dificuldade na linguagem oral.

Essa fase da pesquisa ocorreu em meados de 2014, e a intenção era que, no ano seguinte, os professores dessem continuidade ao emprego da Análise de Desempenho; no entanto, encontramos algumas dificuldades nesse processo. Percebemos que o processo de autoavaliação da prática pedagógica do sujeito que estava em evidência no vídeo ficava um pouco prejudicado, pois todos os participantes assistiam juntos ao vídeo e comentavam suas impressões ao mesmo tempo, não havendo espaço para o professor em cena falar de que forma ele foi impactado ao assistir ao vídeo.

Outra dificuldade encontrada é que, como todos assistiam juntos ao material gravado, não era dado o tempo hábil para que o vídeo chegasse ao final antes de iniciarem os comentários. Dessa forma, apenas um pequeno trecho do vídeo era analisado e logo as professoras começavam a comentar sobre ele, sem esperar para observar o modo como o professor conduzia o desfecho das atividades realizadas. Além dessas questôes relatadas, também houve dificuldade para realizar a análise dos vídeos, pois as três professoras que se propuseram a participar da Análise de Desempenho gravaram cenas com diferentes períodos de duração, não apresentando um padrão para a tabulação dos dados.

A observação desses obstáculos ocorridos durante a Análise de Desempenho possibilitou a elaboração de uma nova pesquisa, que se constitui em uma ramificação do estudo conduzido por Schirmer e Nunes. O trabalho aqui apresentado utilizou a experiência ocorrida durante a Análise de Desempenho das educadoras, em 2014, para propor uma metodologia que favorecesse a formação em serviço de professores.

A principal justificativa de um novo estudo foi a necessidade de uma abordagem que viabilizasse o registro das práticas educativas dos professores de SRM, para que eles pudessem adentrar no cotidiano de sua sala de aula e realizar um processo reflexivo acerca de suas práticas com alunos que não apresentam fala funcional. 


\section{O uso da autoscopia como aliada no processo de formação de professores}

Pensar em um processo de formação de professores que tenha a sala de aula como principal laboratório para que a formação aconteça não é tarefa fácil. Conforme vivencia as questôes que emergem de seu cotidiano, o professor mergulha e envolve-se em sua prática pedagógica, de modo que se torna difícil perceber, por si só, as mudanças necessárias. Desse modo, faz-se necessário utilizar uma ferramenta que permita uma observação com o devido distanciamento, possibilitando que ele reveja suas posturas e (re)formule o modo como ensina e planeja suas aulas.

Sendo assim, ao perceber todas as dificuldades encontradas durante a etapa da Análise de Desempenho, a pesquisadora (primeira autora) aprofundou-se nos estudos sobre a autoavaliação, realizada a partir de um conteúdo videogravado, e utilizou-se dessa técnica para que os professores pudessem meditar sobre suas ações e realizar a avaliação de suas práticas pedagógicas. Foi assim que a pesquisadora encontrou estudos que utilizavam a autoscopia como forma de avaliação docente e, a partir dessa técnica, iniciou a construção de uma pesquisa de dissertação derivada dos estudos de Schirmer e Nunes, cujo objetivo principal foi analisar como o processo de autoscopia na formação continuada dos professores de Salas de Recursos Multifuncionais influencia suas práticas pedagógicas.

Os objetivos específicos foram os seguintes: descrever e analisar a interação de dois professores com os alunos atendidos nas SRMs e verificar os efeitos da introdução da autoscopia (como procedimento para efetivar a formação continuada desses professores) nas interações professor-aluno em situação de ensino.

Em sua origem literal, a palavra "autoscopia" é composta pelos termos "auto" e "scopia". O termo "auto" é empregado quando uma ação é realizada pelo próprio sujeito, e "scopia" refere-se a escopo (do grego skoppós e do latim scopu), que significa objetivo, finalidade, meta, alvo ou mira. Portanto, ao realizar a autoscopia, o participante terá oportunidade de avaliar sua prática pedagógica após a observação de seu próprio desempenho ao interagir com um desses alunos na SRM. Essa tarefa foi possibilitada pelo registro em vídeo de trechos de seu atendimento a esses alunos. 
Sadalla e Laroca (2004) descrevem a autoscopia como uma técnica que se faz em dois momentos: o primeiro ocorre durante a gravação do vídeo e o segundo acontece quando o sujeito assiste ao material gravado para, então, realizar a análise do que foi visto.

De acordo com as autoras, o processo de autoscopia pode ser descrito da seguinte maneira: vale-se do recurso de videogravação de uma prática, visando à análise e à autoavaliação por um ou mais protagonistas dessa prática. Por meio da videogravação, objetiva-se apreender as ações do ator (ou atores), o cenário e a trama que compõem uma situação. O material videogravado é submetido a sessões de análise a posteriori da ação, o qual se destina à apreensão do processo reflexivo do ator (ou atores), por meio de suas verbalizações durante a análise das cenas videogravadas (2004, p. 421).

Segundo Leite (2012), “a Autoscopia é um procedimento de coleta de dados conhecido como confrontação de si na tela”, no qual, por intermédio das gravações realizadas e após a edição do material, o sujeito "é colocado em uma situação para observar o material gravado, sendo estimulado verbalmente pelo pesquisador para emitir comentários em razão dos objetivos da pesquisa" (Leite, 2012, p. 358).

\section{Participantes e local do estudo}

A pesquisa foi realizada com duas professoras que estão lotadas nas SRMs do município do Rio de Janeiro, que também fazem parte da pesquisa coordenada por Schirmer e Nunes, e com dois alunos que não possuem a fala funcional. As duas educadoras participantes são do sexo feminino e, neste trabalho, serão identificadas como Célia (C) e Glória $(\mathrm{G})$. A professora Célia tem 30 anos de idade e seis anos de experiência no magistério, sendo quatro anos com atuação em SRM; cursou faculdade de Pedagogia, fez especialização em Psicopedagogia, mestrado em Educação e, no momento, está cursando o doutorado em Educação. Glória tem 29 anos e sua experiência no magistério é de cinco anos, sendo três deles dedicados à atuação na SRM; concluiu recentemente a graduação em Ciências Biológicas.

Os alunos de Célia e Glória serão identificados, respectivamente, como Arthur e Heitor. Os dois são do sexo masculino e possuem laudo de autismo 
infantil. Eles estão matriculados em duas escolas distintas de ensino comum da Secretaria Municipal do Rio de Janeiro. Na época da pesquisa, Arthur encontrava-se com onze anos e estava matriculado no terceiro ano do ensino fundamental. Já Heitor, com sete anos, frequentava o segundo ano.

Os vídeos utilizados na pesquisa foram coletados na SRM de duas escolas públicas da rede municipal do Rio de Janeiro. As sessões de autoscopia ocorreram na OV do IHA e no Laboratório de TA da UERJ, conforme disponibilidade de espaço para os encontros.

Para realizar a filmagem dos atendimentos aos alunos, as professoras utilizaram seus próprios celulares e, para gravar as sessões de autoscopia, uma filmadora digital.

Como esta pesquisa é uma ramificação do estudo conduzido por Schirmer e Nunes (2013), os procedimentos aqui empregados já contavam com a aprovação do Comitê de Ética em Pesquisa da UERJ (número 336.622, de $11 / 7 / 2013)$. As professoras participantes da pesquisa preencheram o Termo de Consentimento Livre e Esclarecido (TCLE) e solicitaram que os responsáveis legais dos dois alunos também o fizessem.

\section{Procedimentos específicos da autoscopia}

\section{Organização prévia:}

A organização dessa etapa envolveu dois momentos: primeiramente, foi solicitado aos professores participantes que filmassem as sessões de atendimento aos seus alunos na Sala de Recursos. As sessões deveriam conter de trinta a trinta e cinco minutos, e a gravação deveria ocorrer de forma ininterrupta. Após a gravação dos atendimentos feitos com alunos sem fala funcional, os professores deveriam enviar os vídeos para a pesquisadora analisá-los previamente, possibilitando, assim, que a totalidade do material fosse contemplada, e não apenas uma pequena parte.

Após assistir ao vídeo por completo, a pesquisadora selecionou algumas cenas contendo situações importantes para a discussão, nas quais a ocorrência das variáveis do estudo pudesse ser mensurada. As cenas elencadas pela pesquisadora tinham, em média, a duração de dez a doze minutos. $\mathrm{O}$ vídeo entregue pelos professores foi editado e recortado, contendo apenas 
as cenas escolhidas pela pesquisadora. A edição do material não continha o mesmo número de cenas para cada vídeo, pois a duração padronizada de cada uma delas não seria relevante para a análise. Em vez de determinar o mesmo número de cenas para serem expostas durante a autoscopia, a pesquisadora decidiu por determinar o tempo de recorte dos vídeos. Portanto, dos trinta minutos contidos em cada gravação, a pesquisadora separou algumas cenas, que totalizaram de dez a doze minutos, e foram essas as que os professores assistiram durante as sessões de autoscopia.

Após fazer o recorte das cenas, a pesquisadora analisou-as cuidadosamente a fim de observar e tomar nota dos pontos que seriam discutidos com os professores durante as sessões de autoscopia.

\section{Realização da autoscopia}

Após a análise e o recorte das cenas, os participantes e os agentes de intervenção encontraram-se para realizar as sessões de autoscopia. Durante as sessões, a apresentação dos vídeos para todos os participantes foi igualmente filmada, para posterior análise da fala emitida pelas professoras ao observarem o modo como realizavam suas práticas pedagógicas e se relacionavam com seus alunos. Nesses encontros, a autora de cada vídeo foi solicitado a avaliar seu próprio desempenho, assim como o de seu aluno. Os demais professores e agentes de intervenção foram igualmente estimulados a comentar sobre o vídeo assistido e dar sugestóes.

O estudo realizado constituiu-se em duas fases, descritas a seguir:

\section{Linha de Base}

As sessōes de Linha de Base foram filmadas pelas duas professoras em seus locais de trabalho. Na primeira fase, foram realizadas três gravações consecutivas das aulas ocorridas nas SRMs (com média de 30 minutos de duração em cada sessão), em que as próprias professoras filmaram os atendimentos aos alunos. Ao se decidir que cada professora realizaria a sua filmagem, foi considerada a interferência que uma pessoa estranha poderia causar ao aluno observado e, com isso, modificar as respostas dele e da própria professora na situação de ensino. Essas três primeiras gravações aconteceram sem que as professoras recebessem qualquer tipo de instrução ou sugestão da pesquisa- 
dora. No entanto, vale ressaltar que, embora as professoras não tenham sofrido intervenção direta durante essa fase, elas já haviam participado do curso de formação continuada oferecido por Schirmer e Nunes junto à OV do IHA. Sendo assim, as duas já apresentavam conhecimento prévio em relação à comunicação alternativa e ao atendimento de alunos com TEA.

Após o término das sessões de Linha de Base, as professoras entregaram o material para a pesquisadora analisar e realizar o recorte das cenas, conforme o que foi descrito anteriormente.

\section{Intervenção}

A realização da Intervenção ocorreu após a pesquisadora editar os vídeos da Linha de Base. Nessa etapa da pesquisa, as professoras deram início ao processo de autoscopia, observando suas práticas pedagógicas por meio do material videogravado. A pesquisadora, a professora Leila Nunes e os membros que compunham a OV estavam presentes nas sessões e a eles foi dada a liberdade de tecer comentários durante o processo de análise do material das professoras.

A Intervenção foi dividida em dois momentos: Autoscopia de Treinamento e Autoscopia Orientada. O primeiro teve a duração de três encontros (ocorridos no período de um mês, sendo um a cada semana), nos quais foi analisado e discutido um vídeo da Linha de Base. As sessões duraram, em média, três horas cada, e as professoras realizaram o exercício de treinar o olhar para perceber as diversas situações cotidianas da sala de aula. Nesse momento, as educadoras foram convidadas a verbalizar sobre o modo como conduziam o atendimento aos seus alunos e como eles respondiam às propostas feitas por elas. Os encontros foram filmados e, posteriormente, transcritos, com o objetivo de analisar a fala das professoras ao perceberem-se atuando com seus alunos.

Após o término da última sessão da Autoscopia de Treinamento, as professoras filmaram uma de suas aulas e entregaram o vídeo para a pesquisadora fazer a seleção de cenas e, assim, dar início ao processo de Autoscopia Orientada. Nessa etapa, em vez de gravarem um conjunto de sessões consecutivas, as professoras passaram, inicialmente, pelo processo de autoscopia e, após, elas retornaram às suas salas para realizarem novas filmagens, de modo 
que, depois de cada gravação, era realizado um encontro para a realização da autoscopia, e assim por diante.

Nesse momento da pesquisa, as professoras receberam orientação direta da pesquisadora, focalizando as variáveis dependentes escolhidas para compor o estudo. Em vez de observarem o vídeo livremente, como foi feito na etapa da Autoscopia de Treinamento, o material foi analisado de acordo com o direcionamento e a orientação dados pela pesquisadora, sendo, por isso, essa etapa considerada como uma Autoscopia Orientada. Os encontros foram filmados e transcritos a fim de exibir a riqueza de detalhes contidos na fala das professoras ao se observarem nos vídeos. Cada sessão de Autoscopia Orientada teve a duração de, aproximadamente, três horas, estando presentes apenas as professoras e a pesquisadora.

Para realizar a edição das cenas dessa fase, a pesquisadora seguiu os mesmos passos descritos anteriormente.

\section{Delineamento da pesquisa}

Com o objetivo de verificar os efeitos do emprego da autoscopia no desempenho das professoras e dos seus respectivos alunos, foi empregado no estudo um delineamento quase experimental intrassujeitos - linha de base e intervenção. Essa metodologia "realiza uma avaliação individual e rigorosa dos efeitos das intervençóes ou tratamentos para cada participante, ou seja, a análise dos efeitos da(s) Variável(eis) Independente(s) em cada caso individual" (Nunes e Walter, 2014, pp. 4-5).

\section{Variáveis}

O emprego dos procedimentos da autoscopia constituiu a Variável Independente (VI).

Baseando-se nos estudos de Nunes et al. (2013), Corrêa Netto (2012), Feuerstein (1980) e Lidz (1991), a pesquisadora propôs cinco categorias de respostas como Variáveis Dependentes (VD), sendo elas: 1) professora favorece a comunicação do aluno; 2) aluno se comunica com a professora; 3) aluno faz uso de diferentes funções comunicativas; 4) desempenho acadêmico do aluno; e 5) prática pedagógica do profissional. 
A pesquisa desenvolveu-se de modo a verificar se VI afeta as VDs, ou seja, se a autoscopia provoca modificações nas práticas do professor e se isto influencia o comportamento e a comunicação dos alunos. Cada VD envolvia um conjunto de respostas, conforme a descrição a seguir:

1. Professora favorece a comunicação do aluno. Os seguintes comportamentos integram esta categoria:

- utilização de cartões para incentivar a comunicação da criança - o profissional faz uso de cartóes de Comunicação Alternativa para elaborar as perguntas e estabelecer algum diálogo com a criança, de modo que ela tenha condições de se expressar;

- utilização de cartões para mediar atividades pedagógicas - o profissional faz uso de recursos de Comunicação Alternativa para adaptar materiais e conduzir atividades de cunho pedagógico, a fim de facilitar a aprendizagem da criança, mas sem a intenção de estabelecer um diálogo com ela;

- espera da resposta da criança - o profissional aguarda a resposta da criança ao se dirigir a ela, dando o tempo necessário para ela conseguir se expressar;

- resposta às perguntas/solicitações da criança - o profissional está atento aos sinais verbais e não verbais emitidos pela criança, de modo a poder responder àquilo que a criança deseja, pergunta ou solicita. O professor percebe o que a criança solicita e dá a ela um feedback, independentemente de atender ou não ao pedido.

2. Aluno comunica-se com a professora. Os seguintes comportamentos integram esta categoria:

- iniciativa de interação com o profissional de modo autônomo - se o aluno inicia o ato comunicativo com o profissional a partir de atitude e interesse próprios, podendo ser de modo verbal ou não verbal;

- resposta ao diálogo iniciado pelo profissional - se o aluno faz uso de elementos verbais e não verbais para responder às perguntas e estabelecer algum diálogo com o profissional; 
- resposta ao direcionamento dado pelo profissional - o aluno entende a solicitação do profissional e responde à atividade proposta por meio de elementos verbais ou não verbais.

3. Desempenho acadêmico do aluno. Os seguintes comportamentos integram esta categoria:

- permanência na tarefa - o aluno mantém-se envolvido na tarefa acadêmica proposta;

- comportamento desafiador e/ou provocativo - o aluno apresenta comportamentos, tais como gritar e olhar para o interlocutor; colocar objetos na boca como se fosse engolir; subir na mesa ou cadeira; levantar com frequência para ser abordado; correr pela sala para ser abordado; fugir da sala para ser seguido; dar leves tapas para ser inquirido; apagar a luz como forma de finalizar a atividade; jogar objetos no chão como forma de recusar a atividade proposta; virar-se de costas para o professor e colocar os dedos no ouvido na tentativa de ignorar o que ele fala etc. Sem cunho de agressividade, mas para ter a atenção voltada para si.

4. Aluno faz uso de diferentes funções comunicativas. Os seguintes comportamentos integram esta categoria:

- pedido de objeto - se o aluno realiza algum ato ou emissóes verbais, ou se utiliza cartôes de comunicação para solicitar um objeto concreto desejado;

- pedido de ação/consentimento - se o aluno realiza algum ato ou emissões verbais, ou se utiliza de cartôes de comunicação para solicitar a execução de uma ação. Inclui pedido de ajuda e outras ações que envolvem outra pessoa, fazendo com que o aluno interaja com o interlocutor.

5. Categorias pedagógicas do profissional. Os seguintes aspectos integram estas categorias, de acordo com Lidz (1991):

- funcionalidade: o professor se preocupa em oferecer uma atividade que possa ser aplicada na vida diária do aluno, dando 
significado/função aos conteúdos pedagógicos apresentados - o conteúdo e a atividade aplicados podem ser generalizados pelo aluno e utilizados em seu cotidiano;

- intencionalidade: o professor fornece mensagem clara para os alunos com a intenção de envolvê-los em uma lição - estar ciente daquilo que pretende ensinar, demonstrando clareza durante a atividade;

- motivação: o professor mantém, com sucesso, a atenção dos estudantes ao longo da atividade, despertando o seu interesse e sua percepção naquilo que lhe está sendo oferecido - consegue motivar a atenção do aluno por meio do uso de voz, gestos, expressões afetivas e material concreto;

- flexibilização: a organização ou o plano de aula do professor podem sofrer alteraçôes de acordo com o comportamento demonstrado pelo aluno - abrir mão de uma atividade planejada ao perceber outro assunto que exija mais atenção e tendo mais significado para o aluno.

As variáveis foram mensuradas com três instrumentos diferentes para que os dados da pesquisa fossem explorados de acordo com suas especificidades. A maior parte das VDs foi mensurada de acordo com a frequência ocorrida em intervalos de três minutos, totalizando 21 minutos de análise para cada variável.

As variáveis que identificam o rendimento acadêmico do aluno (mantém a atenção durante a realização da atividade e apresenta comportamento desafiador) foram medidas em termos de sua duração. Tal medida permite verificar se houve aumento ou diminuição da duração de tais comportamentos.

As quatro subcategorias da variável referentes ao planejamento e à prática pedagógica do professor (Funcionalidade, Intencionalidade, Motivação e Flexibilização) foram mensuradas por meio de uma Escala Ordinal do tipo Likert, pontuada de 1 a 4, proposta por Lidz (1991). No quadro abaixo, estão descritas as categorias. 
Figura 1 - Escala ordinal utilizada por Lidz (1991)

\begin{tabular}{|c|c|c|c|}
\hline 4 & 3 & 2 & 1 \\
\hline $\begin{array}{c}\text { Comportamento } \\
\text { evidente em alto } \\
\text { grau }\end{array}$ & $\begin{array}{l}\text { Comportamento } \\
\text { evidente de forma } \\
\text { moderada }\end{array}$ & $\begin{array}{l}\text { Comportamento } \\
\text { evidente de forma } \\
\text { emergente }\end{array}$ & $\begin{array}{l}\text { Comportamento } \\
\text { não evidente }\end{array}$ \\
\hline
\end{tabular}

Ao lado de cada subcategoria analisada, foi apresentada uma escala ordinal, conforme figura anterior. Ao observar a variável de "funcionalidade", por exemplo, a pesquisadora avaliou se esse comportamento apresentou-se de forma evidente em alto grau, em grau moderado, de forma emergente ou não evidente nas gravaçõos realizadas pelos professores.

\section{Resultados da Autoscopia de Treinamento}

O cotidiano dinâmico da sala de aula exige do professor um constante planejamento de suas açóes. Conforme assume uma postura rotineira e reproduz suas atitudes de maneira automática, corre o risco de seguir acreditando que não há nada a mudar em sua prática pedagógica. A proposta para essa etapa da pesquisa foi descortinar o olhar das professoras, fazendo com que elas tivessem a coragem de olhar para seu próprio desempanho, sendo capazes de identificar os desafios que emergem da prática pedagógica.

Durante essa etapa, foi possível perceber a dificuldade de as professoras considerarem a necessidade de mudanças em suas práticas e posturas. No início da pesquisa, elas apresentavam um planejamento rígido e engessado, de modo que não havia espaço para a flexibilização da rotina e das atividades propostas, mas, aos poucos, as duas professoras saíram da posição de ensinantes para assumirem, também, a posição de aprendizes, de modo que uma prática retroalimentasse a outra.

Pouco a pouco, foi possível perceber que as professoras adentraram na proposta da autoanálise e no processo reflexivo de suas práticas pedagógicas.

Para ilustrar tal postura, vejamos agora uma das cenas selecionadas pela pesquisadora para a análise autoscópica. Ela foi apresentada no primeiro 
encontro da Autoscopia de Treinamento e fazia referência a uma atividade conduzida pela professora Célia (C) com seu aluno Arthur (A).

A cena tem início com a professora apresentando para o aluno três copos, numerados de 1 a 3, e um pote com tampinhas de refrigerante. A atividade consistia em identificar o numeral nos copos e colocar dentro deles a quantidade de tampinhas correspondente:

C: Olha aqui o que a gente vai fazer (mostrando a caixa com tampinhas).

O aluno brinca com uma boneca e não olha para a professora.

C: Não é a boneca não. Olha, são essas pecinhas aqui. Tá vendo? Tem tampinhas.

O aluno continua brincando com a boneca, sem prestar atenção na professora.

A professora mostra os copos para o aluno e diz:

C: Vamos colocar as tampinhas aqui dentro.

O aluno insiste em brincar com a boneca, e a professora retira o brinquedo de suas mãos.

O aluno pega a caixa com tampinhas, e a professora diz:

C: Assim você vai derrubar [...] Você não quer deixar eu te ajudar? Primeiro, vamos parar a teimosia e depois, a gente vai fazer direito.

O aluno coloca as tampinhas dentro do copo de modo indiscriminado e deixa os copos caírem no chão.

C: Pode guardar tudo porque não quero mais fazer isso não. Porque não é assim que se faz. Você tá vendo como tá tudo errado? Não tá nem na hora de brincar. Eu sei que você quer brincar com a boneca, mas eu já disse que não. 
Ao iniciar o processo de autoscopia, a professora alegou que aquele foi o primeiro dia em que esteve sozinha com o aluno, por isso, ele ainda não estava habituado à rotina e não respeitou a ordem dada por ela. Após ouvir a fala da professora, a pesquisadora disse que o que mais chamou sua atenção durante a cena foi a insistência em fazer com que o aluno se envolvesse com uma atividade que parecia não fazer sentido para ele. A outra professora sujeito da pesquisa (Glória - G.) também estava presente e, ao ouvir o comentário da pesquisadora, questionou sobre o limite entre insistir com o aluno e deixar que ele faça apenas aquilo que quiser. Célia concordou com o comentário feito por sua colega e acrescentou que abrir mão da atividade é "dar margens para que o aluno faça apenas aquilo que ele tiver interesse e vontade". A partir dessas falas, a pesquisadora aproveitou para trabalhar o conceito de "funcionalidade", utilizado por Suplino (2005).

Com essa visão de educação centrada no professor, os atendimentos das professoras eram inflexíveis, e não havia espaço para a troca de saberes com os alunos, fazendo até mesmo com que eles apresentassem poucas intenções comunicativas devido a essa postura rígida assumida por elas.

Em algumas situações, os alunos conseguiram demonstrar iniciativa na comunicação e sinalizavam seus interesses particulares. As professoras costumavam dar atenção e respondiam às solicitações feitas por eles, mas as respostas eram, na maioria das vezes, uma negação ao pedido dos alunos e, com isso, elas perdiam a oportunidade de estimular a autonomia comunicativa deles. Quando a professora apresenta uma fala do tipo "Eu sei que você quer brincar com a boneca, mas eu já disse que não", ela não cria a possibilidade de o aluno se expressar, pois não há uma devolutiva de modo que ele entenda o porquê daquilo não ser permitido.

O próximo exemplo, refletido junto às professoras durante o primeiro dia da Autoscopia de Treinamento, também retrata um momento no qual a professora não considerou o pedido do aluno e manteve o planejamento que havia feito. A cena teve início quando a professora Glória $(G)$ apresentou para seu aluno uma garrafa de plástico e propôs que ele pintasse o objeto fazendo uso de cola colorida e pincel. Esse seria um presente a ser entregue como lembrança do Dia das Mães. 


\section{Presente para a mamãe}

A professora inicia a atividade entregando para o aluno um pincel para que ele pintasse um objeto que seria entregue como presente de dia das mães. $\mathrm{O}$ aluno estava bastante inquieto e não demonstrava interesse pela atividade. Ele soltou todo o material e olhou fixamente na direção da parede.

G: Eu sei que você tá querendo fazer outras coisas. Eu sei o que você quer. Você quer o livro. Você quer usar o computador. Mas, só vamos usar o livro e o computador, depois que pintar o presente da mamãe. Vamos terminar de pintar?

O aluno pega o pincel e volta a pintar a garrafa.

G: Isso! Muito bem. Pega mais tinta.

Ao ouvir isso, o aluno coloca as mãos no ouvido e emite um suspiro que indica cansaço

G: É, não adianta tampar os ouvidos, vamos terminar de pintar. Segura aí o pincel e vamos continuar a atividade.

Vale a pena ressaltar que, durante a cena apresentada, o aluno já havia pintado a garrafa quase em sua totalidade, mas a professora insistia para que ele pintasse mais. Após assistir ao vídeo, a professora explicou a nós que o seu objetivo era trabalhar a mistura de cores, pois ela havia colocado duas tintas no potinho e pedido para que o aluno misturasse. Como o aluno se manteve disperso durante a maior parte do tempo, ao assistir a cena, a professora percebeu que seu objetivo não tinha sido alcançado, pois o aluno demonstrava estar interessado em outras coisas.

A pesquisadora chamou a atenção para a seguinte fala da professora: "Eu sei o que você quer". Glória usou essa frase quando o aluno apontou para a parede na tentativa de mostrar algo a ela. Em seguida, a pesquisadora perguntou como a professora poderia ter tanta certeza, como ela realmente sabia o que o aluno desejava. A fala da professora continha a informação de que era preciso terminar de pintar a garrafa para mudar a atividade, mas 
talvez o aluno considerasse que a atividade já estivesse concluída e, naquele momento, ele tentava expressar que desejava fazer outra coisa.

Ao ouvir essa fala, Célia comentou que caímos na mesma questão da cena em que o aluno recusava a atividade das tampinhas: "Quem deve decidir o tempo da atividade? Somos nós ou é o aluno? Se ele apontar para a rotina e quiser mudar, a gente deve deixar que ele faça o que quer?”.

Por meio dos comentários das professoras, podemos, mais uma vez, perceber o quão inflexível elas eram no início da pesquisa. Heitor apontou para outro objeto e demonstrou uma clara intenção de se comunicar, mas a professora não reconheceu essa possibilidade e insistiu na atividade de pintura. A cena também retrata que, no princípio, as professoras utilizavam os cartôes de CAA apenas como meio de organização pedagógica na condução de atividades, não havendo espaço para o desenvolvimento e a expansão da linguagem.

Ao final da terceira Autoscopia de Treinamento, foi solicitado às professoras que partilhassem a experiência vivida ao longo dos três encontros - o que elas sentiram ao se olharem nos vídeos e como elas se percebiam. Por meio de suas respostas, foi possível perceber a proporção da importância de ter uma prática crítico-reflexiva, visto que esse processo torna viável a mudança de atitude e a postura pedagógica.

A professora Célia respondeu à pergunta com lágrimas nos olhos. Ela ficou muito emocionada ao relatar como foi difícil esse processo de deixar que entrássemos em sua sala de aula para observarmos, juntos, o cotidiano de sua prática. Célia chorou ao contar que a observação de suas ações fez com que ela percebesse que é preciso mudar a cada dia e que não podemos ser sempre os mesmos:

C: No início da proposta da pesquisa eu estava toda animada, mas depois me bateu uma depressão, me veio uma tristeza, e eu pensei: 'Caramba, o que eu estava fazendo com esse menino?'. [...] 'Por que eu estou levando tampinha se o menino não gosta nem de tampinha?' [...] Aos poucos eu fui percebendo que a prática é muito mais ampla do que eu focava, a prática de comunicação alternativa é uma imensidão. [...] Isso é bom, pra gente tomar uma rasteira. Eu pensei: 'Está vendo como não adianta fazer iniciação cientifica? Se você, na prática, não mudar, não vai adiantar nada o conhecimento teórico que você tem. E se não fosse a sua 
pesquisa e a oportunidade que eu tive de me olhar através dos vídeos, talvez eu estaria batendo na mesma tecla das tampinhas até agora'.

O depoimento da professora Célia causou um grande impacto na equipe de pesquisa, pois, durante o processo do estudo, não conseguimos contemplar em sua totalidade o quanto os procedimentos adotados puderam contribuir para a formação humana e profissional do docente. Após a partilha de Célia, foi a vez da professora Glória nos contar como foi a sua experiência durante essa etapa de treinamento:

G: Desde a primeira filmagem que passou eu morri de medo e vergonha, mas hoje eu só tenho a agradecer pela autoscopia. Porque na hora a gente não percebe aquela tentativa incessante de tem que dar certo e ai continuamos a insistir na atividade que planejamos, sem levar em consideraçāo a possibilidade de mudança. Durante todo esse tempo eu só tenho a agradecer às mudanças que a pesquisa causou no meu trabalho. Porque eu não conseguia perceber a quantidade de formas que você tem de chegar no aluno. Hoje eu percebo que, por mais que a minha mudança seja uma coisa sutil, isso modifica muito a vida da criança e ela pode aprender melhor de acordo com o modo que vou ensiná-la.

Dessa forma, terminamos a etapa da Autoscopia de Treinamento e combinamos como seria o prosseguimento da pesquisa. Após o terceiro encontro, depois de terem passado pela experiência de observar suas práticas, foi solicitado às professoras que gravassem novas sessões para análise. Ao contrário da etapa anterior, os novos vídeos não deveriam ser gravados em sequência, pois, antes de coletar novos dados em seus locais de trabalho, as professoras passariam pelo processo de análise do material. ${ }^{4}$

Essa etapa fomentou nas professoras a importância da formação continuada baseada em um processo de autoanálise. A prática da autoscopia propiciou que elas experimentassem o processo de reelaboração de suas práticas pedagógicas a partir do confronto criado entre a imagem retratada no vídeo e o cotidiano da sala de aula.

4 Essas novas sessões de análise foram observadas e mensuradas e constituíram a fase de Intervenção. 


\section{Resultado da Autoscopia Orientada}

Até o presente momento, foram apresentados alguns relatos verbais feitos pelas professoras ao se observarem atuando nos vídeos. Podemos perceber, pela fala delas, o movimento feito na tentativa de melhorar suas práticas pedagógicas. No entanto, para ter maiores evidências de como ocorreu esse processo, foi realizada a mensuração das seguintes variáveis diretas: 1) professora favorece a comunicação do aluno; 2) aluno comunica-se com a professora; 3) aluno faz uso de diferentes funções comunicativas; 4) desempenho acadêmico do aluno; e 5) prática pedagógica do profissional.

Embora a pesquisadora tenha realizado a edição dos vídeos e feito o recorte de algumas cenas a fim de serem analisadas durante a autoscopia, foi considerada a totalidade de cada vídeo para o momento de mensuração das variáveis.

As três variáveis referentes à comunicação foram mensuradas de acordo com a frequência do comportamento ocorrida em intervalos de três minutos. As gravações realizadas pelas professoras tinham a duração aproximada de trinta minutos. As variáveis foram medidas até o sétimo intervalo, totalizando 21 minutos (contínuos) de análise para cada variável. As variáveis continham algumas subcategorias, o que contabilizou o total de nove categorias observadas em cada sessão.

Ao averiguar a variável referente ao modo como as professoras favorecem a comunicação do aluno, foi possível perceber que, no início da pesquisa, na maioria das vezes, os cartóes de CAA eram utilizados apenas com a intenção de mediar e adaptar atividades pedagógicas, não considerando as questôes mais abrangentes de comunicação. Havia uma acentuada dificuldade para usar o cartão como forma de comunicação e promoção do diálogo com os alunos. Após o processo de intervenção, observamos o aumento das tentativas em fazer com que a CAA favorecesse a comunicação de forma efetiva, sendo os cartôes usados como um instrumento que possibilitasse a interação dos alunos com o meio e com seus pares, por meio da expressão de seus pensamentos e desejos.

Ao refletirem como realizavam suas práticas pedagógicas e como se relacionavam com seus alunos, as professoras perceberam a necessidade de voltar o olhar para aquilo que eles tentavam comunicar por meio de suas ações. 
Mediante essa nova postura, é possível observar na Tabela 1, a seguir, as mudanças que ocorreram na frequência média do comportamento de espera das respostas dos alunos pelas professoras na Linha de Base e na Intervenção.

Tabela 1 - Frequência média do comportamento de espera das respostas dos alunos pelas professoras na Linha de Base e na Intervenção

\begin{tabular}{|l|l|l|}
\hline & Linha de Base & Intervenção \\
\hline Célia & 10 & 24 \\
\hline Glória & 7 & 18 \\
\hline
\end{tabular}

A Tabela 1 revela que houve um aumento no tempo de espera que as professoras ofereciam para as crianças responderem às atividades propostas. Foi possível identificar que as duas mostraram-se mais pacientes e perceberam a importância de saber aguardar a resposta dos alunos, possibilitando que eles se expressassem mais vezes. Ao dar mais tempo para os alunos elaborarem suas respostas, estes tinham mais condições de expressar não só o que as professoras perguntavam, mas também conseguiam manifestar aquilo que desejavam.

Essa atitude de espera por parte das professoras implicou até mesmo o número de vezes que elas atendiam às solicitações das crianças. Na Tabela 2, a seguir, conseguimos observar esse dado de modo concreto:

Tabela 2 - Frequência média das respostas da professora às perguntas/solicitações das crianças na Linha de Base e na Intervenção

\begin{tabular}{|l|l|l|}
\hline & Linha de Base & Intervenção \\
\hline Célia & 18 & 25 \\
\hline Glória & 11 & 20 \\
\hline
\end{tabular}

A partir dos números apresentados, é possível afirmar que as professoras mostraram-se mais atentas aos sinais dados pelas crianças e passaram a responder com maior frequência às perguntas e às solicitaçôes recebidas.

A mudança na postura profissional das professoras permitiu que se percebesse que o comportamento dos alunos tem uma ligação direta com o 
comportamento apresentado pelas docentes, como se uma prática alimentasse a outra. Ao analisar a variável referente à comunicação estabelecida entre o aluno e o profissional, foi possível verificar que as professoras modificaram o seu modo de agir, e os alunos, por sua vez, apresentaram mais respostas e mais intenções comunicativas.

Durante a realização da autoscopia, foi possível acompanhar o gradual empenho das professoras ao buscarem um modo de ensino que fosse agradável aos alunos. No início da pesquisa, as aulas eram centradas no objetivo estipulado por elas e mesmo que os alunos demonstrassem outro tipo de interesse durante a realização das atividades, as professoras insistiam no planejamento preparado e não modificavam a estratégia de ensino.

A maioria das interações estabelecidas pelas professoras visava a conduzir atividades pedagógicas, não havendo espaço para a troca por meio de diálogos. Conforme elas mudavam suas posturas e passavam não só a conversar com os alunos, mas também a ensinar-lhes a fazer escolhas por intermédio dos cartôes de comunicação, era possível perceber o aumento das respostas dadas por eles.

Além da postura dos professores, avaliamos também o comportamento autônomo dos alunos no processo de comunicação. Em relação à variável referente ao uso das funções comunicativas iniciadas pelos alunos, foi possível observar que, no decorrer da pesquisa, os alunos apresentaram um aumento de tais funçôes. A Tabela 3 mostra a frequência média das interações iniciadas pelos alunos de modo autônomo com as professoras nas fases de Linha de Base e de Intervenção.

Tabela 3 - Frequência média das interações que os alunos iniciaram de modo autônomo com as professoras nas fases de Linha de Base e de Intervenção

\begin{tabular}{|l|l|l|}
\hline & Linha de Base & Intervenção \\
\hline Arthur & 6 & 15 \\
\hline Heitor & 4 & 13 \\
\hline
\end{tabular}

É possível perceber que, nas sessões de intervenção, os alunos apresentaram mais autonomia na comunicação, aumentando o número de interações iniciadas por eles. Isso é consequência de todas as mudanças apresentadas anteriormente. Como as professoras apresentaram novos cartôes e construí- 
ram junto aos alunos o significado daqueles símbolos, elas demonstraram a funcionalidade social que os cartões representavam, e os alunos tiveram mais possibilidades de solicitar objetos e açôes que fossem do seu interesse.

Nas sessões gravadas durante a Linha de Base, as professoras ofereceram poucas possibilidades para os alunos realizarem escolhas. Geralmente, elas direcionavam as atividades de modo que os alunos tivessem apenas que executá-las, sem haver espaço para que eles decidissem o que queriam fazer. Dessa maneira, eles não foram estimulados a solicitar os objetos ou ações que desejavam e, quando o faziam, não recebiam um retorno positivo. Fato este que pode ter contribuído para que eles não entendessem o significado do uso dos cartões de CAA.

Após o término da Autoscopia de Treinamento, as professoras passaram a usar os cartôes de CAA como mediadores entre aquilo que elas propunham e a escolha das crianças. Com isso, pudemos perceber o aumento da autonomia comunicativa dos alunos.

Para analisar o desempenho acadêmico dos alunos, optou-se por medir sua duração, de modo a verificar com mais precisão se houve o aumento ou a diminuição dessas respostas. Para isso, foram considerados os primeiros 21 minutos de cada vídeo, de modo que a pesquisadora pudesse observar a frequência de envolvimento dos alunos nas atividades propostas e de emissão de comportamentos desafiadores. Após identificar o número de ocorrências desses eventos, a pesquisadora fez uma breve descrição deles e cronometrou a duração de cada ocorrência.

Para obter o percentual de duração de envolvimento dos alunos com a tarefa, a pesquisadora considerou o tempo total das atividades realizadas e o tempo total em que eles se mantiveram envolvidos na tarefa.

Quadro 2 - Equação realizada para obter a percentagem de duração do envolvimento do aluno na tarefa

Tempo de envolvimento na tarefa/tempo total da tarefa X $100=$ Percentual de duração de envolvimento na tarefa.

Dessa maneira, foi possível organizar os dados com a duração dos comportamentos, de modo a perceber a evolução apresentada pelos alunos ao 
longo da pesquisa. A seguir, encontram-se os dados relacionados à percentagem da duração do envolvimento de Arthur e de Heitor com as tarefas propostas durante as fases de Linha de Base e Intervenção.

Gráficos 1 e 2 - Percentual de duração do envolvimento dos alunos na tarefa durante as fases de Linha de Base e Intervenção
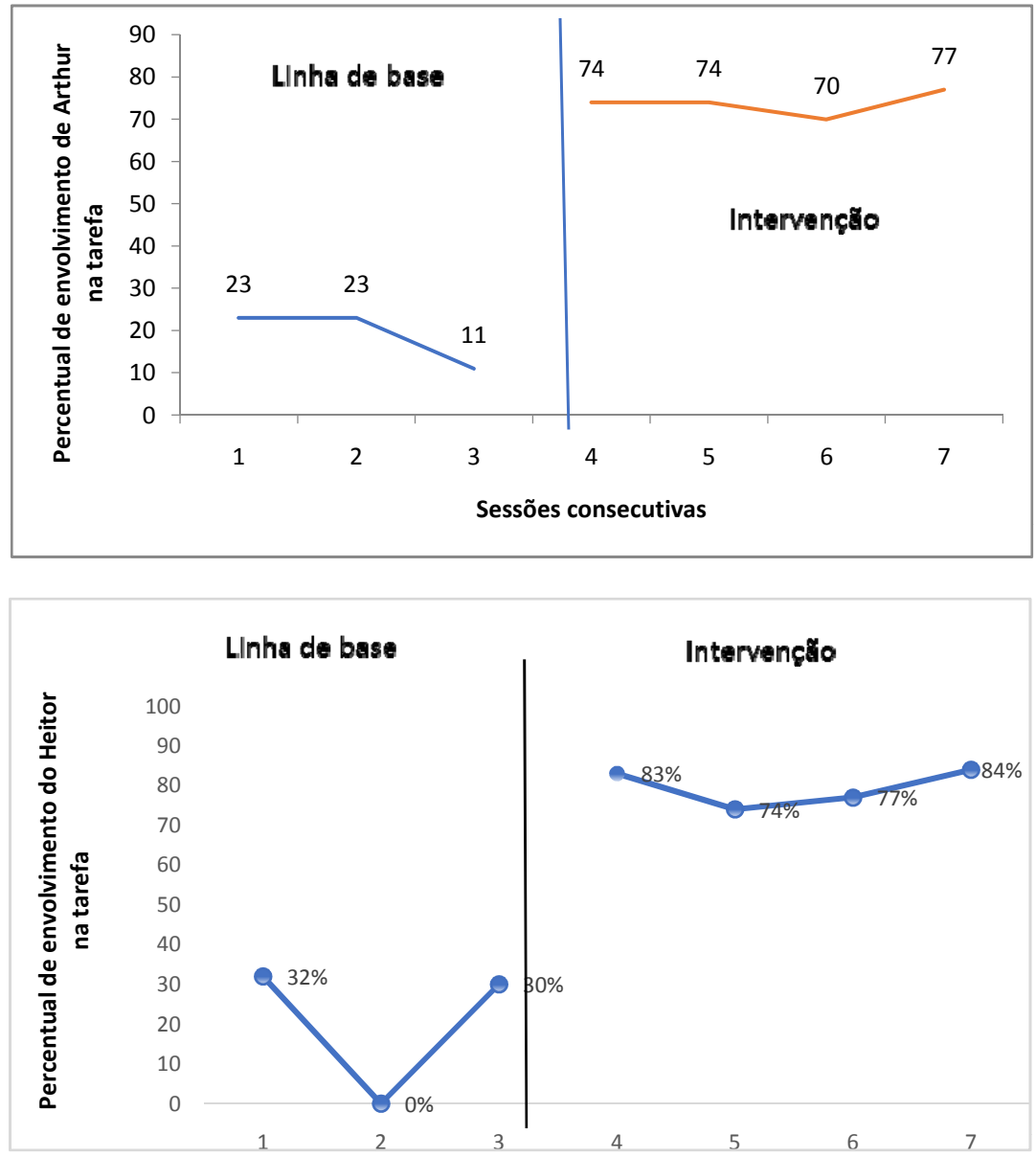

Observando todo o percurso realizado pelos alunos ao longo do ano letivo, pode-se perceber que o aumento do envolvimento nas atividades propostas pareceu ser decorrente do modo como as professoras passaram a conduzir as aulas. Dois fatores podem ter contribuído para isso: a funcionalidade empregada nas atividades, tornando-as úteis para os alunos, e a busca de 
conhecer melhor o gosto deles para, então, oferecer atividades que estivessem no centro de seus interesses.

Paralelamente ao aumento do tempo de envolvimento na tarefa dos alunos, houve a diminuição dos comportamentos desafiadores apresentados por eles. Para obter o percentual do tempo em que os alunos apresentaram esse tipo de comportamento, a pesquisadora considerou a duração total da sessão e a duração dos comportamentos desafiadores, o que resultou na seguinte equação:

Figura 2 - Equação realizada para obter a percentagem de duração dos comportamentos desafiadores dos alunos durante as atividades

\begin{tabular}{|ccc|}
\hline Tempo total de comportamento desafiador & $100=\begin{array}{c}\text { Percentual } \\
\text { de duracão } \\
\text { Tempo total da sessão }\end{array} \begin{array}{c}\text { domportamentos } \\
\text { desafiadores }\end{array}$ \\
\hline
\end{tabular}

Nos Gráficos a seguir, está apresentado o percentual de duração dos comportamentos desafiadores/provocativos dos alunos durante as tarefas na Linha de Base e na Intervenção. 
Gráficos 3 e 4 - Percentual de duração dos comportamentos desafiadores/ provocativos dos alunos durante as tarefas das fases de Linha de Base e Intervenção
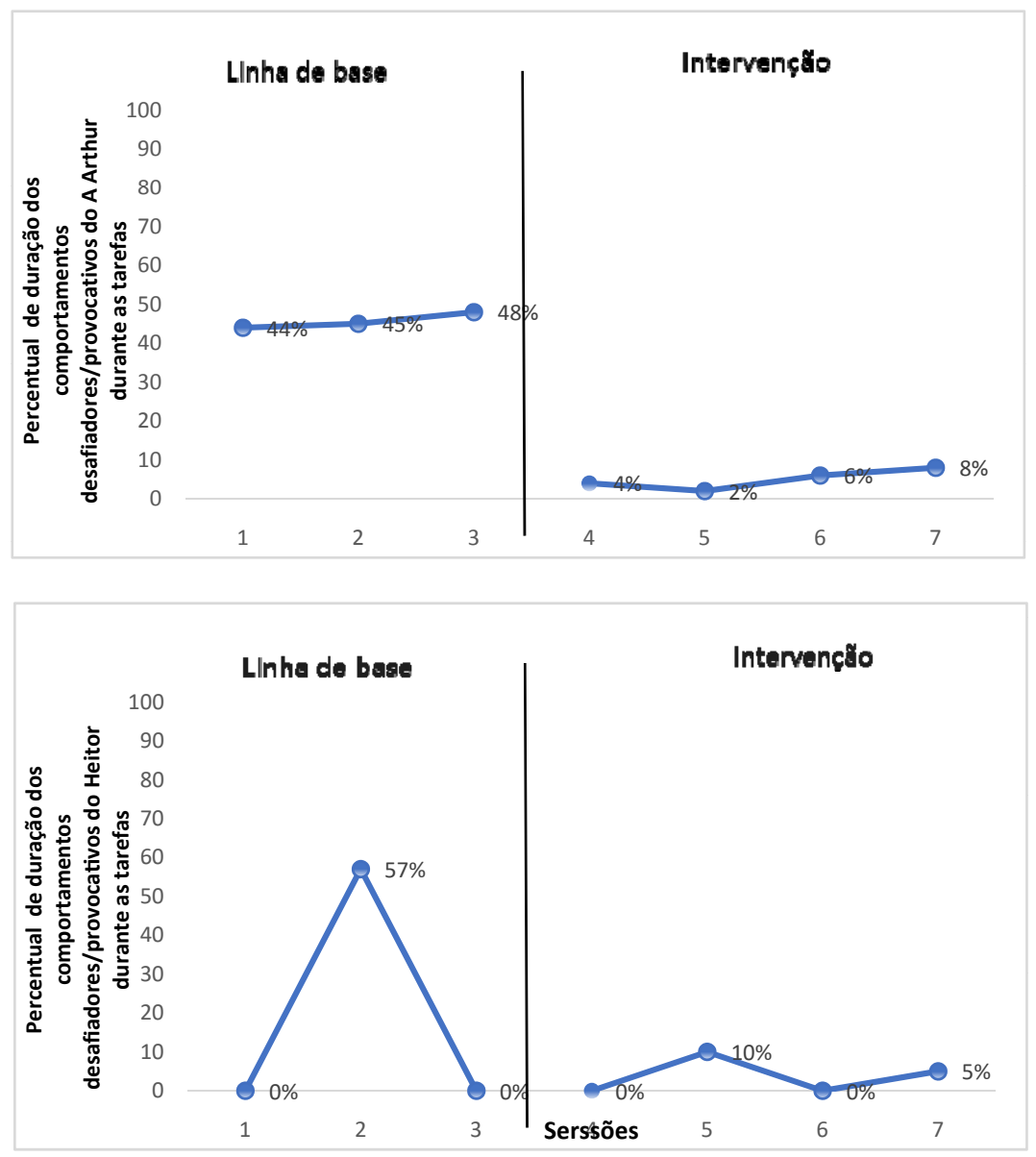

A análise desses dados permite-nos concluir que os alunos passaram a ocupar mais o tempo com a realização de atividades e, com isso, não desafiavam tanto as professoras; pelo contrário, eles começaram a estabelecer uma relação de parceria e troca. Foi justamente na fase de Intervenção que as professoras aumentaram as possibilidades de trabalho com a CAA, incentivando os alunos a usarem novos cartôes e a aumentarem o vocabulário. Dessa maneira, eles começaram a expor seus desejos por intermédio dos 
cartôes, não sendo necessário chamar a atenção por meio de comportamentos desafiadores.

No início da pesquisa, não havia a preocupação das professoras com a funcionalidade das atividades propostas. $\mathrm{O}$ maior cuidado era fazer com que seus alunos acompanhassem o conteúdo curricular referente à turma comum na qual estavam matriculados. Com isso, elas desenvolviam atividades de cunho tradicional e não ampliavam a possibilidade de trabalhar tais conteúdos, de modo a serem aproveitados na vida cotidiana das crianças.

Ao se preocuparem em oferecer atividades que apresentassem alguma funcionalidade na vida dos alunos, as educadoras passaram a planejar melhor as tarefas, demonstrando uma maior clareza daquilo que pretendiam ensinar. Ao terem em mente o conteúdo que seria ensinado, elas começaram a buscar o melhor modo de desenvolver as atividades com os alunos.

Os dados referentes à intencionalidade das professoras durante a execução das propostas pedagógicas também apresentaram mudanças, conforme podemos observar no gráfico que mostra a intencionalidade exibida por Célia e Glória na Linha de Base e na Intervenção. 
Gráficos 5 e $\mathbf{6}$ - Avaliação da intencionalidade apresentada pelas professoras durante as fases de Linha de Base e de Intervenção
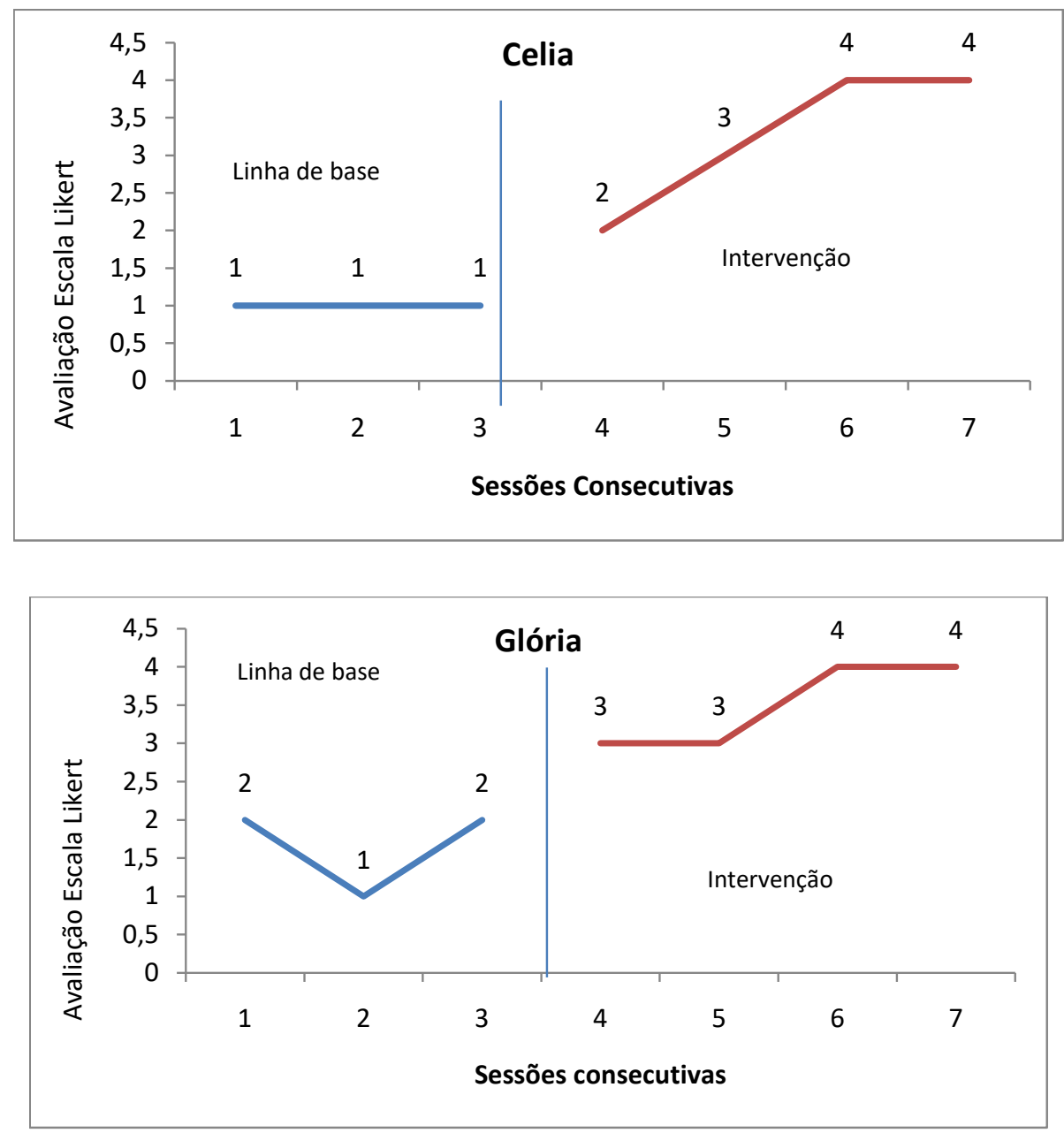

$\mathrm{O}$ aumento da intencionalidade perpassou até mesmo a reorganização do ambiente físico. A princípio, os objetos de interesse dos alunos estavam sempre ao alcance deles, não sendo necessário interagir com as professoras para conseguir aquilo que desejavam. Depois de passarem pelo processo de intervenção, as professoras começaram a deixar os objetos em locais onde os alunos não conseguissem alcançar, obrigando-os, assim, a estabelecerem 
algum tipo de interação ao solicitar aquilo que eles desejavam ${ }^{5}$. Dessa forma, elas demonstraram a intenção de se comunicar com os alunos em diferentes situaçōes, oferecendo pistas verbais e concretas (cartões de CAA) para que eles pudessem solicitar o que queriam.

Com todas essas mudanças atitudinais e físicas, os alunos passaram a se interessar mais pelas atividades propostas. $\mathrm{O}$ início da pesquisa retratou que a prática das professoras não motivava os alunos e que, por diversas vezes, eles reagiam de modo desafiador durante a realização das atividades, ou então, ainda que não apresentassem esse tipo de comportamento, eles não se interessavam por aquilo que era proposto e não conseguiam manter-se envolvidos com a atividade por muito tempo. Conforme as professoras buscaram o ponto de interesse dos alunos, foi possível perceber o aumento do envolvimento deles com o que lhes era proposto.

Ainda em relação às mudanças apresentadas pelas professoras em busca da motivação dos alunos, foi possível perceber que elas passaram a demonstrar mais afeto, usando um tom de voz menos agressivo e estabelecendo contato físico com eles por meio de beijos e abraços. Com essa postura, os alunos passaram a ficar mais motivados e, consequentemente, mantinham uma maior atenção no decorrer das atividades.

Para finalizar a avaliação do desempenho da prática pedagógica das professoras, apresentamos os dados referentes à flexibilização demonstrada por Célia e Glória durante a Linha de Base e a Intervenção.

5 Trata-se de um procedimento do Ensino Naturalístico. 
Gráficos 7 e 8 - Avaliação da flexibilização das propostas pedagógicas apresentadas pelas professoras durante as fases de Linha de Base e de Intervenção
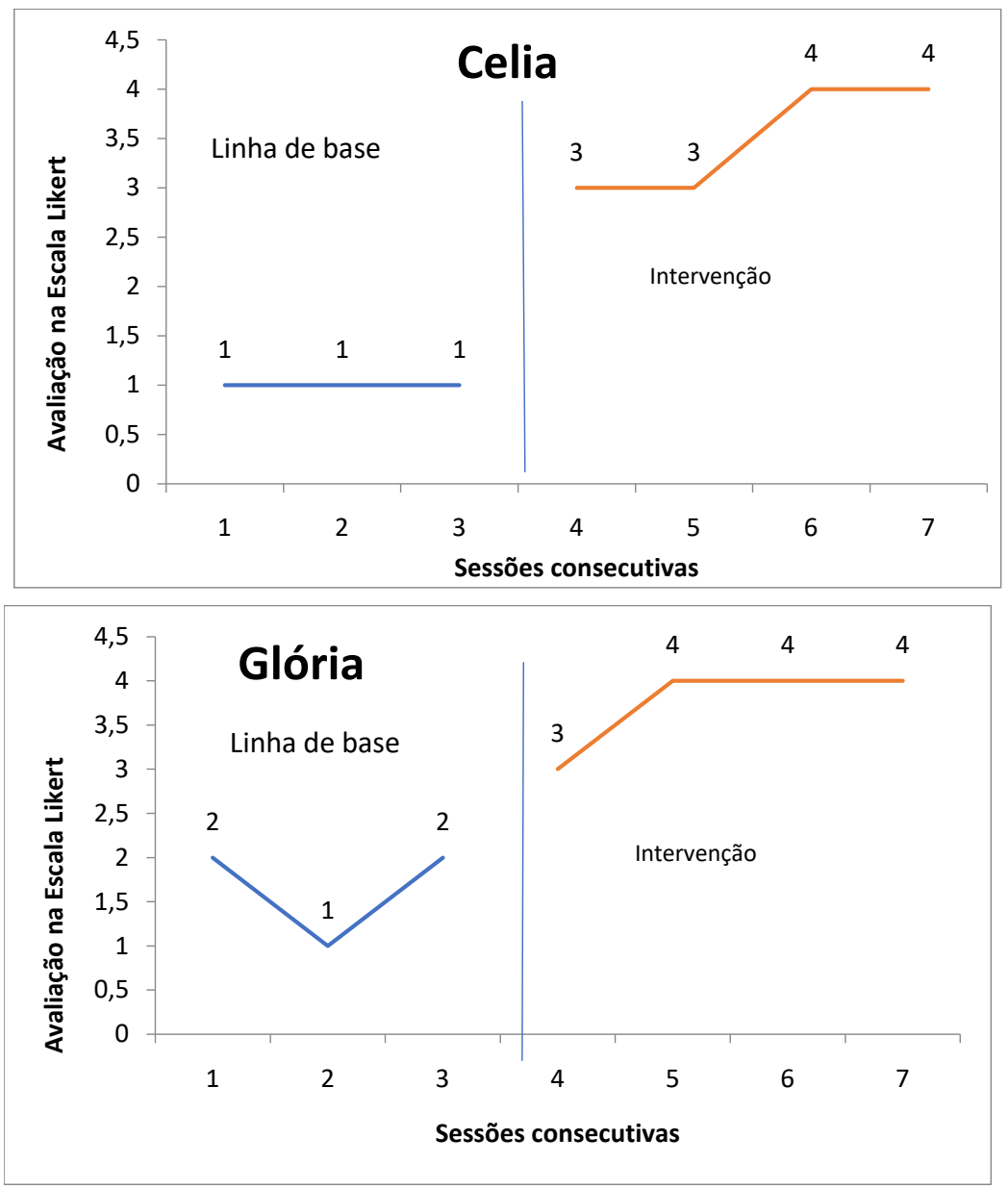

Todas as mudanças apresentadas em relação à prática pedagógica do profissional só foram possíveis porque, anteriormente a essas questões, as professoras decidiram abrir mão de um saber soberano e passaram a acreditar no saber compartilhado. Ao realizarem a autoscopia das sessões de Linha de Base e observarem as cenas que mostravam o modo enrijecido como conduziam suas propostas, as educadoras demonstraram bastante resistência à mudança e argumentaram como se tivessem certeza absoluta de que suas ações eram a melhor opção a seguir. Com o tempo, seus próprios relatos durante 
a autoscopia demonstraram uma abertura à mudança, e isso foi refletido em suas ações. Fato que resultou nos dados constantes nos gráficos anteriormente apresentados.

\section{Conclusão}

Segundo Nóvoa (1991), o desenvolvimento profissional do professor deve ocorrer mediante uma formação crítico-reflexiva, que propicie as dinâmicas de autoformação participada e que colabore para a construção da sua identidade como docente. De acordo com essa concepção de formação, a prática docente deve ir além dos procedimentos meramente didáticos para transformar-se em uma formação consciente e crítica.

$\mathrm{Na}$ tentativa de contribuir para tal, a autoscopia colocou os professores em posição de recomeço, de forma que eles assumissem a postura de rever suas práticas e percebessem a necessidade de estar em contínuo processo de aprendizagem. Aprendizagem esta que, segundo Freire (1997), requer a humildade de reconhecer que "não existe ensinar sem aprender".

Com o passar do tempo, as professoras compreenderam que, para o desenvolvimento de uma linguagem expressa por meio da CAA (e também da língua falada), não basta apenas aprender as correspondências entre os signos e os símbolos gráficos (ou palavras faladas), também é preciso entender como esses signos podem ser utilizados em diversas situaçóes da vida, dando-nos a possibilidade de expressar significados e manter comunicação com as pessoas com as quais convivemos (Von Tetzchner, 1996).

Aos poucos, foi possível perceber que as professoras passaram a considerar as intenções comunicativas das crianças, criando com elas esse caminho alternativo de constituição do sujeito. Conforme elas percebiam a necessidade de dar importância àquilo que os alunos demonstravam por meio de balbucios e gestos, foi possível identificar a diminuição dos comportamentos desafiadores apresentados. A respeito disso, Von Tetzchner et al. (2005) afirmam que, muitas vezes, algo é negado a uma criança que não consegue se comunicar de maneira oral sem que ela compreenda o motivo da negação, ou até mesmo sem que ela saiba se o seu desejo foi interpretado corretamente pelo outro. Segundo esses autores, a prática comunicativa colabora para a 
prevenção do desenvolvimento de comportamentos desafiadores, pois a falta de experiências comunicativas relevantes pode levar as crianças a reagirem emocionalmente às rejeiçôes.

Todas as mudanças ocorridas na postura das professoras, no que concerne ao modo como planejavam e executavam suas ações, podem ser atribuídas à prática da autoscopia. Em relação a isso, Sadalla (1997) preconiza que, por meio da autoscopia, os indivíduos que observam suas imagens no vídeo têm a chance de "alterar, reorganizar ou reformular suas ações, atitudes e posturas”, pois é possível, ao analisar o material gravado, observar o ambiente que o cerca e detectar as causas e efeitos de nossos comportamentos (p. 33).

Um dos grandes ganhos que se pode observar na mudança de atitude das professoras foi a importância que elas passaram a dar para a funcionalidade das atividades propostas. A respeito do currículo funcional, Suplino afirma que "é comum encontrar pessoas portadoras de retardo severo ou autismo que já alcançaram a idade adulta sem, no entanto, serem capazes de realizar tarefas mínimas relacionadas a autocuidados ou autoproteção, por exemplo" (Suplino, 2005, p. 33). Pensar na função e na contribuição que cada tarefa realizada exercerá na vida cotidiana dos alunos fez com que eles passassem a se interessar mais pelo que estava sendo proposto, pois, além de funcionais, as atividades tornaram-se prazerosas, sem o peso do conteúdo curricular que as professoras propuseram na Linha de Base.

Os resultados apresentados durante a realização desta pesquisa permite afirmar que a autoscopia é um meio eficaz para o processo de formação de professores, visto que a reflexão iniciada a partir da observação de suas atuaçôes contribui para a construção da consciência que constituirá a identidade docente. Identidade essa que se refaz a cada dia, em cada diálogo, em cada encontro, em cada experiência vivida com aquele que deve ser o principal motivo do exercício pedagógico: o aluno. 